\title{
ARQUIVOLOGIA/BIBLIOTECONOMIA: INTERFACES DAS CIÊNCIAS DA INFORMAÇÃO ${ }^{1}$
}

Johanna W. Smit

\begin{abstract}
Resumo
Arquivistas, bibliotecários, documentalistas, gestores da informação e museólogos, apesar de diferenciados em termos profissionais e institucionais, contribuem, de forma complementar, para a disponibilização da informação estocada, configurando objetivos comuns. As diferenças que se stabelecem entre os campos de atuação dos arquivistas e bibliotecários geram divergentes procedimentos de tratamento da informação e a discussão daquilo que as une, por meio de suas semelhanças, apontam para objetivos comuns quando as competências de ambos os profissionais, tanto de arquivos como de bibliotecas, visam tornar acessível a informação.
\end{abstract}

\section{Palavras-Chave}

Arquivologia; Biblioteconomia; Ciência da Informação

\footnotetext{
${ }^{1}$ Palestra proferida no "Seminário em Ciências da Informação", promovido pelo Departamento de Ciência da Informação da Universidade Estadual de Londrina, 23 a 25 de agosto de 2001.
} 


\section{INTRODUÇÃO}

Embora o resumo inclua outras profissões, que a meu ver compõem um todo maior, a discussão deverá se ater às duas profissões apontadas pelo título, e respectivas áreas de atuação. A pergunta que o texto a seguir pretende desenvolver pode ser formulada como segue: no que consistem as semelhanças e diferenças entre estes profissionais e seus respectivos espaços institucionais? ${ }^{2}$

Pragmaticamente, partamos da distribuição profissional, consolidada pela tradição, e que distingue nitidamente duas categorias profissionais, respectivas formações e atuações institucionais: os arquivistas e os bibliotecários/documen- talistas. De fato, a distribuição aqui proposta não reflete uma distribuição internacional homogênea, principalmente se lembrarmos que bibliotecários e documentalistas podem constituir categorias muito diversas (na maior parte dos países europeus, por exemplo) ou estarem confundidos na mesma categoria (no Brasil, por exemplo), que os arquivistas podem se distribuir em duas categorias (o "records manager" e o arquivista, como acontece nos EUA, p.ex.) ou numa única categoria. Finalmente, de-

\footnotetext{
${ }^{2}$ Este texto retoma, parcialmente, um artigo publicado na revista "Ciencias de la Información", editado pelo PROINFO/IDICT Cuba, em setembro de 1999.
}

ve-se acrescentar que a mesma categoria pode ter diversas denominações. A categoria dos documentalistas, em particular, diversificou-se ao longo do tempo para um leque de expressões tais como "administradores" ou "gestores da informação", "analistas" ou "especialistas da informação", e assim por diante. A estas duas categorias profissionais associei ainda os museólogos, denominando a família profissional pela expressão "3 Marias" (SMIT 1993), numa tentativa de atingir uma simplificação didática sem pretender refletir o espectro profissional em todas suas nuances. A denominação "3 Marias" visa portanto resumir uma situação, identificando cada categoria profissional como uma Maria e reunindo as três irmãs (uma loira, uma morena e uma ruiva) numa família na qual cada irmã ignora em boa parte a atuação profissional, os princípios teóricos e as metodologias de trabalho das demais.

Voltemos aos arquivistas e bibliotecários. A tradição separa estas categorias profissionais, enfatizando desta maneira as diferenças, ou especificidades e ignorando, conseqüentemente, suas semelhanças. Trata-se, de fato, de um embate entre duas visões distintas, porém complementares: por um lado uma visão calcada nas práticas profissionais, ainda muito ancoradas no paradigma do acervo, e por outro lado, a função social de instituições que coletam, 
estocam e disponibilizam informações. Em outras palavras, trata-se tanto de constatar as diferenças, que se estabelecem entre os campos de atuação profissional, quanto a discussão daquilo que as une, uma vez que se parte do princípio que há "algo" que as une.

\section{AS DIFERENÇAS ENTRE}

\section{ARQUIVISTAS, BIBLIOTECÁRIOS/ DOCUMENTALISTAS}

As práticas profissionais estão de tal forma sedimentadas que cada profissão é vista isoladamente, conta com uma bibliografia própria, congressos e associações próprios, impedindo o fluxo e a troca de informações e, principalmente, impedindo que todos se vejam num contexto maior. $O$ isolacionismo, paradigma problemático da área, prepondera e nos tornou muito mais competentes na denominação das diferenças do que na identificação das semelhanças.

As diferenças se fundamentam em dois grandes eixos complementares: os acervos e as instituições que os abrigam. No imaginário profissional coletivo estocase livros e periódicos em bibliotecas e ao passo que documentos gerados pelas administrações são estocados em arquivos. A frase acima simplifica, de uma forma caricata, o imaginário, mas pretende resumi-lo ao essencial. Em outros termos, a diferenciação se apóia na distinção de tipos (e suportes) documentais, metodologias de organização decorrentes desta distinção e, finalmente, supõe o trabalho de organização da informação sempre adequado aos objetivos institucionais, fechando o círculo vicioso. Ou seja:

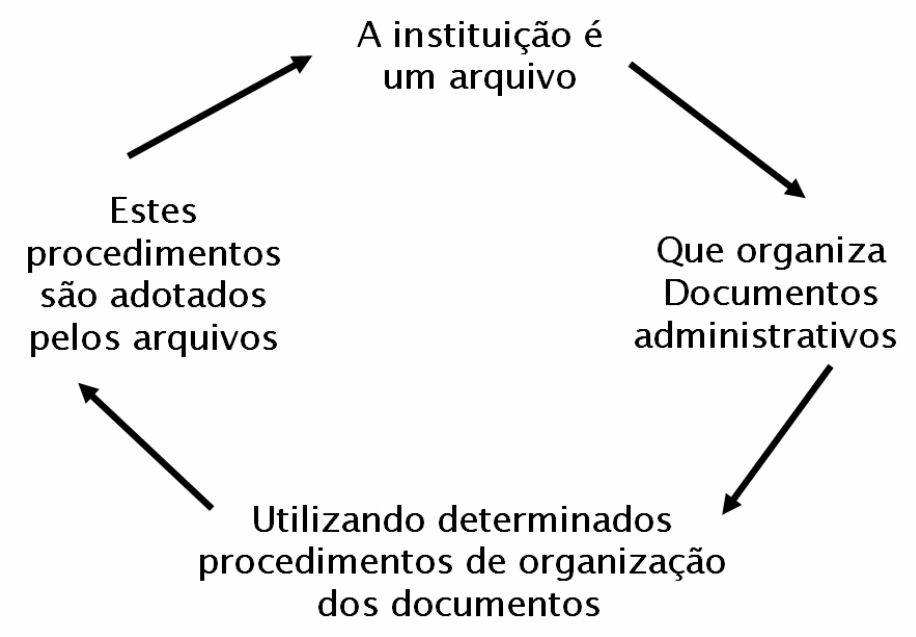

O círculo vicioso, no caso da bibliote- mas características de circularidade: suconomia, manifesta exatamente as mes- põe-se que uma biblioteca organize mate- 
riais bibliográficos, de acordo com procedimentos próprios e característicos da biblioteconomia. A tradição de separação das áreas existe efetivamente e certamente responde a determinadas necessidades da sociedade. No entanto, o peso da tradição deve ser relativizado, enfatizando-se a necessidade de proceder a uma análise da situação que vá além da vivência profissional.

Arquivos e bibliotecas não nasceram separadas, mas foram se afastando ao longo do tempo. Ao que tudo indica, as primeiras instituições acumulavam tanto materiais bibliográficos quanto documentos de natureza arquivística (relações de propriedades de terras e respectivos impostos) (MARTINS, 1996; WITTY, 1973). Somente com a invenção da imprensa e a duplicação mecânica de textos, além do estabelecimento de formatos de papel e composição de cadernos (in-quarto, inoctavo, etc.) os documentos foram adquirindo sua feição atual. A distinção entre bibliotecas e arquivos, em particular, originou-se certamente neste momento, pois baseada numa associação automática e indiscutível entre os tipos documentais e a função da informação neles contida. Detecta-se, a partir desta colocação, um primeiro núcleo de questionamentos possíveis e que pode ser sistematizado ao redor dos termos documento, informação e função. Colocada nestes termos entende-se por que a inclusão da biblioteconomia, documentação e arquivologia no seio das chamadas "ciências documentais" não gerou maiores discussões, uma vez que se afirmava suas diferenças (sem explicá-las) mas se concordava que todas tinham algo em comum: o trabalho com documentos. $\mathrm{O}$ próprio nome determina a importância atribuída ao documento enquanto aglutinador de práticas profissionais e respectivas instituições.

A dupla documento/informação coloca inúmeros problemas e ainda estamos distantes de um dimensionamento satisfatório da questão. Pode-se afirmar que as duas áreas vivem uma constante tensão entre o documento e a informação, ora priorizando um, ora outro. Como enunciar a tensão? De imediato, nota-se um maior apego dos arquivistas ao documento e uma facilidade por parte dos documentalistas para abstrair o documento, enfatizando a informação nele presente. As discussões atuais sobre as bibliotecas virtuais, redes e sistemas de informação resumem o ápice nesta descolagem entre informação e documento. A informação deve ter sido registrada de alguma forma para poder ser estocada. Este é um postulado tão básico para a área que geralmente o mesmo é esquecido. A tecnologia trouxe enormes progressos nas formas de registro e, principalmente, nas formas de organização e transmissão da informação registrada, mas 
a mesma sempre terá sido registrada de alguma forma e estocada em algum lugar ou computador. Não é operacional, portanto, pensar a informação isolada de seu registro, por mais que a questão do registro é muito menos pertinente para o bibliotecário/documentalista e é fundamental para o arquivista uma vez que este deve disponibilizar, além da informação, a prova (o documento). Em resumo, documento e informação são as duas faces da mesma moeda, sendo que uns prestam mais atenção a uma face, outros à outra, mas não é possí-

vel descolar as faces da moeda. As "ciências documentais" geram uma tensão entre documento e informação mas, qualquer que seja a ênfase dada à informação ou ao documento, o paradigma que subjaz a abordagem, tendo por base o documento, ainda é o do acervo, do estoque.

Considerando que o documento, embora comum às duas áreas, não permite objetivamente distinguí-las, proponho submeter a discussão a um ponto de vista diacrônico pelo qual a ênfase no documento é substituída pela ênfase na informação:

Documento $\longrightarrow$ Informação
Acervo $\longrightarrow$ Usuário
Estoque $\longrightarrow \begin{aligned} & \text { Função e utilização da } \\ & \text { informação }\end{aligned}$

Como toda mudança de paradigma, a mesma é muito discutida, muito elogiada, mas ainda não se infiltrou em todas as práticas e todos os raciocínios. O discurso atual - a ênfase no usuário (MORRIS, 1994; VALENTIM, 1995), ainda não provocou a reformulação de nossas distinções profissionais pois neste assunto continuamos formalizando a partir do paradigma do acervo (JARDIM; FONSECA, 1992), sem nos darmos conta que estas distinções não encontram mais fundamentação, ou ancoragem, no discurso atual.
Quando a discussão enfatiza a função atribuída à informação, como modo de distinção entre a arquivologia e a biblioteconomia, aproximamo-nos de um critério menos formal, mais fértil. Na biblioteconomia a função é atribuída aos documentos associando-a ao uso. O documento cumpre sua função quando é usado, lido ou consultado. O mesmo objetivo determina sua seleção, ou seja, o acervo é constituído por documentos que se supõe úteis para alguém em algum momento. A arquivologia enuncia a questão de forma diferen- 
ciada, pois a função determina, ou formata, o documento. Assim sendo, creio poder afirmar que a função atribuída ao documento determina sua "entrada" no sistema arquivístico, ao passo que sua "saída" (o uso) tem sido enfatizado na lógica biblioteconômica. Desnecessário sublinhar que aqui se trata de ênfases, e não de oposições, pois nenhuma coleção de documentos e informações prescinde de uma entrada (é o que forma a coleção, o estoque informacional) e de uma saída (é o que determina sua razão de ser institucional). Nenhuma instituição estoca informações sem ter uma razão para tanto: a prova, o uso, o testemunho.

Se, na ótica arquivística, os documentos são produzidos em decorrência natural das atividades da instituição e estocados para provar, testemunhar ou informar sobre estas atividades, decorre naturalmente desta afirmação que sua organização deverá levar em conta este princípio de organicidade. $^{3}$ Lança-se, portanto, sobre os documentos, um olhar que priorize as atividades da instituição: os documentos foram gerados para que essas atividades fossem realizadas e são organizados em função destas atividades, dos responsáveis pelas

\footnotetext{
3 Organicidade: "qualidade segundo a qual os arquivos refletem a estrutura, funções e atividades da entidade acumuladora em suas relações internas e externas" (CAMARGO; BELLOTTO, 1996, p.57).
}

mesmas e de quem os acumulou: é o conceito da "proveniência". 4

$\mathrm{Na}$ biblioteconomia o olhar lançado sobre os documentos é outro, pois a preocupação com as razões de sua geração são consideradas inoperantes, irrelevantes ou desconhecidas. Enfatiza-se a informação contida nos documentos e a utilidade que esta pode revestir para um grupo social ou institucional.

Dito em outros termos, se na arquivologia a função do documento é definidora de sua entrada no sistema de informação e posterior organização, na biblioteconomia enfatiza-se sua função no momento da saída do sistema. Conseqüentemente, organiza-se os documentos de acordo com outro parâmetro: a informação neles contida.

O museólogo Homulos (1990) sinaliza pistas norteadoras para o debate, ao recusar o estabelecimento de fronteiras rígidas entre museus, arquivos e bibliotecas e propor uma organização destas instituições ao longo de um grande contínuo tendo as bibliotecas numa extremidade, os museus na outra e os arquivos no meio do contínuo. $\mathrm{Na}$ acepção do autor cada instituição, de acordo com o momento, se colocaria preponderantemente numa lógica ou noutra. $\mathrm{O}$ autor menciona, dentre outros, um critério

\footnotetext{
${ }^{4}$ Proveniência: "instituição ou pessoa legitimamente responsável pela produção, acumulação ou guarda de documentos" (CAMARGO; BELLOTTO, 1996, p.63).
} 
que distingue as instituições, ou seja, o "conteúdo informacional" de cada uma: na biblioteca a coleção dos documentos representa a própria informação estocada ao passo que no arquivo os documentos informam sobre a instituição que os acumulou.

Homulos denomina o conjunto formado pelos arquivos, bibliotecas e museus "Instituições coletoras de cultura". Se o texto de Homulos significou um grande avanço, ao tornar as fronteiras entre as instituições fluidas, a expressão "coletor de cultura" direciona novamente para o estoque, ou o acervo.

Em função do acima exposto, embora as diferenças entre instituições existam, e não possam ser ignoradas, as mesmas encontram sua fundamentação teórica principal no paradigma do acervo.

3 ALÉM DO ACERVO, O QUE SEPARA AS 3 MARIAS?

O gerenciamento de estoques informacionais, e sua utilização, pode ser distribuído em 3 grandes grupos de atividades:

- Gestão da memória - seleção, coleta e avaliação de documentos e estoques informacionais;

- Produção de informação documentária - representação da informação esto- cada e conseqüente produção de informação documentária (bases de dados, catálogos, resumos, etc.);

- Mediação da informação - a comunicação de informações objetivando uma efetiva transferência da informação, em função das necessidades informacionais dos usuários.

Este modelo subentende uma distinção entre a informação produzida e registrada pela sociedade (o "input" do sistema) e a informação produzida pelos arquivos e bibliotecas ("output 1" do sistema), objetivando propiciar o acesso às informações estocadas ("output 2" do sistema). A informação produzida por arquivos e bibliotecas será denominada "informação documentária", pois é produto de um trabalho de natureza documentária, ou representacional, e não deve ser confundido com a informação produzida pelos demais segmentos da sociedade e estocada nas instituições. A distinção é necessária pelas seguintes razões:

- Distingue as responsabilidades das diferentes informações gerenciadas ou disponibilizadas pelas instituições (DESANTES GUANTER, 1987);

- Marca a complementaridade entre as duas "informações", assumindo-se que a informação documentária constitui um elo na cadeia do fluxo e utilização da informação. Em outros termos, a informa- 
ção documentária é um meio para um fim, ou seja, o acesso à informação estocada.

Arquivos e bibliotecas atuam nas 3 atividades, pois todas decidem o que deve ser estocado (gestão da memória) e produzem uma informação documentária como meio para uma utilização da informação estocada (mediação). No entanto, a partir de características institucionais e características intrínsecas aos estoques informacionais, as instituições nomeiam e enfatizam diferentemente as atividades. Se as bibliotecas trabalham, em regra geral, com unidades informacionais (autores e títulos de livros, p. ex.), a unidade de refe- rência em arquivos é a série, ou seja, "uma seqüência de unidades de um mesmo tipo documental", sendo que o tipo documental é a "configuração que assume uma espécie documental, de acordo com a atividade que a gerou" (CAMARGO; BELLOTTO, 1996, p.69 e 74). O princípio norteador da organização dos documentos é igualmente variado, uma vez que na biblioteca o critério do "assunto" predomina, enquanto que nos arquivos o critério é o da estrutura organizacional da instituição, acoplado à função administrativa exercida pelos documentos. A título de exemplo, e sem pretender à exaustividade, o quadro abaixo ordena algumas atividades realizadas no âmbito de arquivos e bibliotecas:

\begin{tabular}{|c|c|c|}
\cline { 2 - 3 } \multicolumn{1}{c|}{} & \multicolumn{1}{c|}{ Arquivologia } & \multicolumn{1}{c|}{ Biblioteconomia } \\
\hline Gestão da memória & $\begin{array}{l}\text { Produção e avaliação } \\
\text { de documentos } \\
\text { - Temporalidade das sé- } \\
\text { ries documentais }\end{array}$ & $\begin{array}{l}\text { - Formação e desenvolvimen- } \\
\text { to de acervos } \\
\text { - Gerenciamento de recursos } \\
\text { informacionais }\end{array}$ \\
\hline $\begin{array}{c}\text { Produção da informação } \\
\text { documentária }\end{array}$ & Processamento técnico & $\begin{array}{l}\text { Representação e recupera- } \\
\text { ção da informação }\end{array}$ \\
\hline Mediação da informação & - Jurisdição e acesso \\
- Programas de difusão & $\begin{array}{l}\text { - Serviços ao usuário } \\
\text { - Ação cultural }\end{array}$ \\
\hline
\end{tabular}

Além das diferenças apontadas pelo quadro acima (e que são em parte terminológicas, e não conceituais), as atividades recebem ênfases, ou pesos, diferenciados entre arquivos e bibliotecas. Correndo o risco da simplificação, parece evidente que a "produção da informação documentária" ocupa posição de destaque nas $3 \mathrm{Ma}$ rias: hoje considerada meio, a mesma já foi associada a um fim em si e certamente 
explica a ênfase (ou quase total predominância) de matérias de "processamento técnico" nos currículos tradicionais de formação biblioteconômica, razão pela qual a mesma alcançou um estágio mais avançado nesta atividade. No entanto, no mesmo esforço de síntese, detecta-se na arquivologia uma preocupação muito grande com a "gestão da memória", o que se explica porque os arquivos devem gerenciar enormes massas documentais e, ao longo do tempo, foram depurando critérios de avaliação destas massas documentais visando decidir o destino e a temporalidade das séries documentais. A arquivística moderna vai além, desenvolvendo uma postura pró-ativa, no sentido de recusar o papel passivo de "receptáculo" de documentos produzidos pela instituição e tender a influir no processo de geração dos documentos, estabelecendo neste momento uma evidente interface com a área de O\&M. Os bibliotecários não desconhecem a importância da gestão da memória, mas são mais "reféns" da sociedade neste quesito, pois não dispõem, em geral, de meios eficazes para influir na geração de documentos. Na "mediação da informação", entretanto, forçoso é constatar que esta atividade foi mais desenvolvida pelos museólogos, que sempre refletiram muito sobre "o que mostrar" e "como mostrar" (CASH, 1988). "Mostrar o acervo", enquanto modalidade de mediação, configura uma área na qual os museólogos investiram certamente mais que arquivistas e bibliotecários, perseguindo, em geral, além de objetivos informacionais, outros, de natureza estética ou sensorial.

Estabelecidas, de forma preliminar as diferenças, tentaremos apontar para as semelhanças entre as instituições, seus respectivos objetivos e profissionais.

\section{O QUE UNE A ARQUIVOLOGIA À BIBLIOTECONOMIA?}

A área de conhecimento da Ciência da Informação apresenta um problema de base gerado pela indefinição de seu objeto, a "informação". Como o termo é utilizado em muitos contextos e acepções diferentes, torna-se imprescindível distinguir a informação estocada por arquivos e bibliotecas de outras "informações", caracterizando-a pela adoção de duas condições:

- No que diz respeito aos arquivos, o registro da informação é condição necessária para a realização de suas atividades, sendo que a informação estocada em bibliotecas é uma informação intencionalmente registrada. Há uma nuance neste aspecto, mas a informação em ambos os casos foi registrada porque alguém, alguma instituição, assim o quis ou necessitou. Esta acepção da informação impede a adoção de abordagens muito amplas e conseqüen- 
temente inoperantes para os objetivos da Ciência da Informação, tais como a informação estética ou a informação genética;

- A informação é estocada por arquivos e bibliotecas em função de uma utilidade que Ihe foi conferida. Supõe-se, em suma, que determinada informação poderá ser necessária ou útil no futuro (enquanto informação, prova, testemunho, etc.) e por esta razão a mesma é intencionalmente estocada. Vale dizer que os estoques informacionais são o produto de uma decisão sobre a utilidade conferida a determinada informação (BUCKLAND, 1991): esta decisão é obviamente relativa e passível de mudanças ao longo do tempo ou em função de momentos institucionais. ${ }^{5}$

De forma resumida, pode-se portanto estabelecer que a informação estocada em arquivos e bibliotecas é registrada e, após avaliação, considerada útil: o fruto deste processo é a institucionalização da informação uma vez que decorrente de decisões institucionais (ou, por extensão, sociais). Independentemente de suportes ou códigos, a informação é institucionalizada

\footnotetext{
${ }^{5}$ Assim como determinadas informações são valorizadas, ou menosprezadas, numa linha temporal (a história da vida cotidiana, p. ex., se alimenta de informações que não teriam sido estocadas numa ótica da "memória do vencedor ou do poderoso") outras, em determinados momentos históricos, são consideradas de alguma forma uma ameaça ao Estado ou à ordem pública e por esta razão são censuradas.
}

por arquivos e bibliotecas: este é certamente um produto da área, que confere "status" a certas informações e o nega a outras. A informação, ao ser institucionalizada em nome de uma utilidade que lhe foi atribuída, é organizada em nome de objetivos institucionais. A institucionalização da informação encontra sua justificativa cultural, social e econômica à medida que esta informação é disponibilizada para a sociedade, ou comunidade, que financia a manutenção do estoque. De forma precisa Mason (1990, p.125) resume o objetivo perseguido pelo profissional da informação e suas instituições: "disponibilizar a informação certa, da fonte certa, para o usuário certo, no prazo certo, numa forma considerada adequada para o uso e a um custo justificado pelo uso". Esta frase, em função do acima exposto, se aplica perfeitamente aos arquivistas e bibliotecários.

\section{CONCLUSÃO}

Do que precede conclui-se que há, além das diferenças, semelhanças. As diferenças, determinadas por funções diferentes atribuídas aos documentos de arquivo e biblioteca geram, por sua vez, procedimentos de tratamento da informação diferenciados. As semelhanças, por seu lado, podem ser detectadas quando a discussão parte para um nível de generalidade maior, e se vislumbra, para além das diferenças, 
objetivos comuns aos arquivos e às bibliotecas, a saber, a disponibilização da informação de forma tal que, quando esta for necessária ou procurada, a mesma possa ser encontrada. A função última de arquivos e bibliotecas, qual seja, a mediação da informação estocada, requer uma visão sistêmica da função da informação na sociedade, conhecimentos acerca de sua geração, organização e circulação social. Em última análise, a meu ver, tanto arquivos quanto bibliotecas são mediadoras de informações, as instituições estocam informações, as organizam produzindo informação documentária, e ambas servem à sociedade através do resgate da informação certa na hora certa. Tanto os profissionais de arquivos quanto de bibliotecas constroem pontes entre informações e cidadãos: nem um nem outro detém o poder, ambos concorrem para tornar a informação acessível e, desta maneira, contribuir para a melhoria da condição humana.

\section{6 ÚLTIMAS PALAVRAS}

Reconhecer as diferenças mas também enfatizar as semelhanças entre a arquivologia e a biblioteconomia significa considerar que ambas desempenham paradigmas competentes da Ciência da Informação (INGWERSEN, 1992). Diante das controvérsias geradas pelas múltiplas definições da "informação" e da "Ciência da Informação" creio pertinente introduzir algumas considerações finais:

- as necessidades informacionais dos cidadãos-usuários dificilmente se enunciam em termos estritamente "biblioteconômicos" ou "arquivísticos";

- o mercado de trabalho vive enormes mutações, afastando-se a passos rápidos das distribuições anteriormente implantadas entre profissões regulamentadas.

A área de conhecimento denominada da "Ciência da Informação" (e suas modalidades pragmáticas, como a arquivística e a biblioteconomia) somente será reconhecida em sua utilidade social quando a mesma conseguir propor soluções para problemas de acesso à informação. Propor soluções novas para problemas tão velhos quanto a própria humanidade supõe o domínio de princípios, teorias, regras gerais, ou seja, o domínio dos conceitos norteadores da Ciência da Informação, além da competência específica para, em função de contextos e situações específicas, conseguir avaliar as melhores soluções, saber implantá-las e avaliá-las criticamente em seu retorno para a sociedade. Propõe-se, em síntese, a imperiosa necessidade de competências específicas aliada ao conhecimento da função e importância da informação para a sociedade. Enquanto interfaces das Ciências da Informação, em suma, 
a arquivologia e a biblioteconomia só têm a ganhar se resgatarem a dimensão conceitual da Ciência da Informação.

\section{REFERÊNCIAS}

BEARMAN, D. Experience delivery services. In: CONGRESSO NACIONAL DE BIBLIOTECARIOS ARQUIVISTAS E DOCUMENTALISTAS, 5, 1994. Lisboa. Anais... Lisboa: Associação de Bibliotecários Arquivistas e Documentalistas, 1994. Arquivos, v. 2, p.153-159, 1994.

BEARMAN, T. C. The education of archivists: future challenges for schools of library and information science. Journal of Education for Library and Information Science, v.34, n.1, p.66-72, 1993.

BUCKLAND, M. Information as thing. Journal of the Americam Society for Information Science, v.42, n.5, p.351-360, 1991.

CAMARGO, A. M. de A.; BELLOTTO, H. L. Dicionário de terminologia arquivística. São Paulo: Associação dos Arquivistas Brasileiros - Núcleo Regional de São Paulo/SEC, 1996.

CASH, J. Picture power: optical discs and video computing come of age. Museum News, p.58-60, jul./ago. 1988.

DERVIN, B., NILAN, M. Information needs and uses. Annual Review of Information Science and Technology, v.21, p.3-33, 1986.

DESANTES GUANTER, J. M. Teoria y régimen jurídico de la documentación. Madrid: Eudema, 1987. (Eudema Universidad: Manuales).

HOMULOS, P. Museums to libraries: a family of collecting institutions. Art Libraries Journal, v.15, n.1, p.11-13, 1990.

INGWERSEN, P. Conceptions of information science. In: VAKKARI, P.; CRONIN, B.
Conceptions of library and information science: historical, empirical and theoretical perspectives. London: Taylor Graham, 1992. p.299-312.

JARDIM, J. M.; FONSECA, M. O. As relações entre a arquivística e a ciência da informação. Cadernos BAD, n.2, p.29-45, 1992.

LEONHARDT, H. A. What is library material, what archive material and what museum material: an attempt at the categorization of documentation materials and institutions. Bibliotheksdienst, v.23, n.8/9, p.891-904, 1989.

MARTINS, W. A palavra escrita: história do livro, da imprensa e da biblioteca, com um capítulo referente à propriedade literária. 2.ed. São Paulo: Ática, 1996.

MASON, R. O. What is an information professional? Journal of Education for Library and Information Science, v.31, n.2, p.122138, 1990.

MORRIS, R. C. T. Toward a user-centered information service. Journal of the American Society for Information Science, v.45, n.1, p.220-230, 1994.

MUELLER, S. P. M. Em busca de uma base comum para formação profissional em biblioteconomia, ciência da informação e arquivologia: relato de um simpósio promovido pela Unesco. Revista de Biblioteconomia de Brasília, Brasília, v.12, n.2, p.157-165, 1984.

PINHEIRO, L. V. R. Em busca de um caminho interdisciplinar: proposta de um núcleo teórico e prático de disciplinas comuns aos cursos de biblioteconomia, museologia e arquivologia. Rio de Janeiro, 1995. In.: REUNIÃO BRASILEIRA DE ENSINO DE ARQUIVOLOGIA, 3, São Paulo, 1997.

SILVA, A. M. da. et al. Arquivística: teoria e prática de uma ciência da informação. Porto: Afrontamento, 1998. 
SMIT, J. W. O documento audiovisual ou a proximidade entre as três Marias. Revista Brasileira de Biblioteconomia e Documentação, São Paulo, v.26, n.1/2, p.81-85, 1993.

. Eu, bibliotecário, RG xxxxx e CPF yyyyy, trabalho em arquivo ou museu... algum problema? Palavra-Chave, São Paulo, n.8, p.12-13, 1994.

TEES, M. Harmonization of education and training programmes for library, information and archival personnel: a report of the Colloquium held in London, 9-15 August 1987. IFLA Journal, v.14, n.3, p.243-246, 1988.

Harmonization of education and

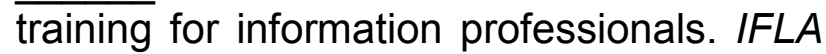
Journal, v.17, n.3, p.232-234, 1991.

VALENTIM, M. L. P. Assumindo um novo paradigma na biblioteconomia. Informação\&Informação, Londrina, v.0, n.0, p.2-6, 1995.

WITTY, F.J. The beginnings of indexing and abstracting: some notes towards a history of indexing and abstracting in Antiquity and the Middle Ages. The Indexer, v.8, n.4, p.193-198, 1973.

\section{Johanna W. Smit \\ Professora da ECA/USP cbdjoke@usp.br}

\section{Title}

Archivology / Library Science: Information Science interfaces

\section{Abstract}

Despite of being different in professional and institutional ways, archivists, librarians, docu- mentalists, information managers and museologists, contribute, in a complementary manner, to make stock information available, configuring, in this way, common objectives. The differences established between the archivists and librarians' professional fields generate different procedures of information treatment and the discussion of the idea that unifies them, based on its similarities, indicates common objectives when the competence of both professionals, in archives as well in libraries, aim to make information available.

\section{Keywords}

Archivology; Library Science; Information Science

\section{Titulo}

Archivología / Bibliotecología: Interfaces de las Ciencias de la Información

\section{Resumen}

Archivistas, bibliotecarios, documentalistas, gestores de la información y museólogos, a pesar de diferenciados en termos profesionales e institucionales, contribuyen, de forma complementar, para la disponibilización de la información almacenada, configurando objetivos comunes. Las diferencias que se establecen entre los campos de actuación de los archivistas y bibliotecarios generan divergentes procedimientos de tratamiento de la información y la discusión de aquello que las une, por medio de sus semejanzas, apuntan para objetivos comunes cuando las competencias de ambos los profesionales, tanto de archivos como de bibliotecas, visan tornar accesible la información.

\section{Palabras Clave}

Archivología; Bibliotecología; Ciencia de la Información.

Artigo recebido em: 23/08/2001 